\title{
Intellectual disability stigma and initiatives to challenge it and promote inclusion around the globe
}

Katrina Scior ${ }^{1}$, Aseel Hamid ${ }^{1}$, Richard Hastings ${ }^{2}$, Shirli Werner ${ }^{3}$, Catherine Belton ${ }^{1}$, Adebisi Laniyan ${ }^{1}$, Maya Patel ${ }^{1}, \&$ Maria Kett ${ }^{4}$

${ }^{1}$ Division of Psychology \& Language Sciences, University College London, Gower Street, London WC1E 6BT (k.scior@ucl.ac.uk; aseel.hamid@ucl.ac.uk;

catherine_belton@hotmail.co.uk; ms.a.laniyan@gmail.com; maya.patel.12@ucl.ac.uk

${ }^{2}$ CEDAR, University of Warwick (r.hastings@warwick.ac.uk)

${ }^{3}$ Paul Baerwald School of Social Work \& Social Welfare, The Hebrew University of Jerusalem (shirli.werner@mail.huji.ac.il)

${ }^{4}$ Leonard Cheshire Disability \& Inclusive Development Centre, University College London (m.kett@ucl.ac.uk)

Corresponding Author:

Katrina Scior PhD, k.scior@ucl.ac.uk

Division of Psychology \& Language Sciences, University College London, Gower Street, London WC1E 6BT

Running title: Intellectual disability stigma around the globe

Key words: intellectual disability, attitudes, stigma, discrimination, intervention

\section{Acknowledgements}

We thank Inclusion International, Leonard Cheshire Disability and IASSID, and Eric Emerson in particular, for their support. We also thank Special Olympics for supporting this project. Finally, we thank all the respondents from around the globe for giving up valuable time to report on the situation in their country.

Funding: This study was funded by UCL's Grand Challenges. 


\begin{abstract}
Background: There is a dearth of studies that have examined the attitudes of society towards people with intellectual disabilities on a global scale.
\end{abstract}

Aims: This study set out to gauge the extent to which intellectual disability continues to be stigmatized and to which initiatives are in place to increase their inclusion and tackle stigma around the globe.

Method: Data were collected using a web survey from 667 experts and organisations in the (intellectual) disability field pertaining to 88 countries and covering all world regions. Information about the study was disseminated by four multinational disability organisations and the survey was available in five languages.

Findings: Responses indicated that the general public in many parts of the world broadly support the fundamental principle of inclusion of children and adults with intellectual disabilities, yet negative attitudes persist. High levels of stigma and denial of fundamental rights still appeared a reality in many places. Initiatives to tackle stigma appeared patchy and least in evidence where they were most needed.

Discussion: In many parts of the world the life chances of people with intellectual disabilities often appear still very poor, and support and advocacy almost entirely their families' responsibility. More needs to be done globally to reduce the stigma associated with intellectual disability and to promote active engagement and regular social interactions between persons with intellectual disabilities and their fellow citizens without intellectual disabilities. 


\section{Introduction}

For people with intellectual disabilities to have equal rights and be fully included in their communities, there must be legislation, policy and structures in place that promote inclusion, as well as accessible services including education, health and social care. The United Nations (UN) Convention on the Rights of Persons with Disabilities (CRPD) (United Nations General Assembly, 2006) is an important step in the direction of providing such legislative structures. In addition though what is needed is a willingness to accept and include people with intellectual disabilities at community and societal level. As Cummins and Lau (2003) and others have noted, achieving physical inclusion in local communities and wider society is important but not sufficient to achieving acceptance and meaningful social inclusion for children and adults with intellectual disabilities (Merrells, Buchanan, \& Waters, 2018; Van Asselt, Buchanan, \& Peterson, 2015; Wilson, Jaques, Johnson, \& Brotherton, 2017). Few comparative global data are available to judge what attitudes are commonly held towards people with intellectual disabilities, to what extent prejudice and discrimination continue to pose major challenges, or what is being done to challenge stigma associated with intellectual disability in line with the CRPD's Article 8. Gauging progress is complicated by the fact that for many countries worldwide, we have no access to published information relating to inclusion and acceptance of people with intellectual disabilities. Evidence on inclusion and the wider societal context of attitudes to intellectual disability is fragmented and mainly derived from high income countries (for a review see Scior, 2011). This is despite the fact that around 80 per cent of people with disabilities live in low and middle- income countries (LMICs) and that intellectual disability, like disability in general, is more common in such countries due to poorer health and maternity care, and increased risk of exposure to diseases, toxins and severe malnutrition (Maulik et al., 2011; World Health Organization, 2011). In many LMICs early screening and access to culturally appropriate diagnostic assessment and support services is 
still limited (Scherzer et al., 2012). As a result, many children and adults with an intellectual disability are not formally identified or diagnosed and have their needs inadequately understood and met.

Previous attempts to compile comparative data specific to intellectual disability from around the globe most notably include Siperstein et al.'s (2003) Multinational Study of Attitudes toward Individuals with Intellectual Disabilities, commissioned by Special Olympics, and the 2007 WHO Atlas: Global Resources for Persons with Intellectual Disabilities. The first of these reports described how people across the world view the roles and capabilities of persons with intellectual disabilities in the classroom, workplace and in daily social life. The study was conducted in 2002 across ten countries (Brazil, China, Egypt, Germany, Ireland, Japan, Nigeria, Northern Ireland, Russia and the United States). The findings, based on a survey of an average of around 800 members of the general population per country, showed that at the time there was clear evidence of negative attitudes - both within and across the countries surveyed - toward persons with intellectual disabilities. The 2007 WHO Atlas, based on 147 responses from $143 \mathrm{WHO}$ member states and territories, highlighted the substantial lack of services available to people with intellectual disabilities worldwide. It also revealed differences between regions in efforts directed at increasing public awareness and the social inclusion of people with intellectual disabilities. Of the 147 countries, 60 per cent reported carrying out public awareness campaigns related to intellectual disability. As we note in this article, we estimate the actual figure to be much lower as closer scrutiny shows that intellectual disability is often not covered in general disability awareness campaigns.

In highly developed countries, attitudes towards persons with intellectual disabilities gradually appear to have become more positive although attitudes vary across countries and longitudinal evaluations are thin on the ground (Scior, 2011; Siperstein et al., 2003). Mixed 
accounts can be found in the literature regarding attitudes to intellectual disability in developing countries. Some anthropological studies have concluded that in rural settings persons with intellectual disabilities are often an integral part of village communities and contribute according to their abilities (Ingstad \& Reynolds Whyte, 1995). Others note that traditional beliefs and misconceptions about the causes of intellectual disability can lead to the persons affected, and often also their families, being viewed with suspicion and to be ostracized from their communities (e.g. Mung'omba, 2008). Mckenzie et al. (2013) suggest that this apparent contradiction may be explained by the severity of intellectual disability and the competence of the person: where they are socially competent and can contribute to the household they may be more accepted. However, if they are highly dependent and seen as a burden on limited family resources, there may be less acceptance, especially in the absence of support services.

The present study's objective was to gather evidence from around the globe on indicators related to the social inclusion of people with intellectual disabilities, attitudes towards them at societal level, and what attempts are being made to raise awareness of intellectual disability, improve attitudes and challenge prejudice and discrimination, as laid out in the CRPD's Article 8, which calls on governments to raise awareness of disability and challenge prejudice and discrimination. The aim of this article is not to present an exhaustive study but rather an attempt to generate a comparative overview of progress towards inclusion, more favourable attitudes, and attempts to improve them in diverse parts of the world. 


\section{Methods}

Data were collected from experts and representatives of organisations in the intellectual disability field and those working in the broader disability field, through a web survey.

\section{Participants}

In total 667 participants gave complete responses to the web survey. Of 720 responses recorded on the survey site, 53 were removed because they were invalid or the respondent attempted to complete the survey twice. Of the final 667 respondents, $44 \%$ described themselves as experts in the intellectual disability field, $28 \%$ as representatives of an organisation focused on people with intellectual disabilities, $19 \%$ as experts in the broader disability field, and $9 \%$ as representing organisations focused on disability in general, not specific to ID. We acknowledge that the latter two groups may not have had the same level of understanding of the situation for people with ID in their country as respondents who worked predominantly in the ID field.

The 667 respondents originated from 88 countries (or independent territories) and represented almost half of the world's countries and all UN defined regions. Different regions were not equally represented within the data, which is not surprising given the much higher resources and expertise on intellectual disability in some world regions. High income countries (based on the four income categories defined by the World Bank according to gross national income per capita in 2013) were over-represented in the data - while $15 \%$ of the world's population live in high income countries, $70 \%$ of respondents were from such countries. The highest number of respondents were from Europe $(n=219)$ and pertained to 27 countries. Data on North America (USA and Canada) were provided by 159 respondents, on Sub-Saharan Africa by 37 respondents, pertaining to 15 countries; and on the Middle East and North Africa 
(MENA) by 28 respondents, pertaining to eight countries, with the majority from Israel $(n=17)$. Asian respondents $(n=40)$ were from 16 countries or territories. Information about South and Central America and the Caribbean was provided by respondents from 16 countries $(n=121)$, and about Australia, New Zealand and Pacific Islands from four countries $(n=63)$. Of responses, $71 \%$ were provided in English $(n=475), 21 \%$ in Spanish $(n=142), 3.4 \%$ each in French and German ( $\mathrm{n}=23$ each), and $0.6 \%$ in Arabic $(n=4)$.

\section{Measures}

The survey was designed by the project team to cover four broad areas: (1) information about the participant and their origin, affiliation and role; (2) information relating to attitudes to intellectual disability and terminology commonly used by the public and media when referring to intellectual disability in the respondent's country; (3) contextual information relating to inclusion of people with intellectual disabilities in the respective country, including education provision for children with intellectual disabilities and the (continuing) existence of residential institutions for adults with intellectual disabilities; (3) information about initiatives designed to tackle acts of abuse, harassment and violence perpetrated against people with intellectual disabilities; and (5) information about initiatives aimed at raising awareness and promoting positive attitudes towards people with intellectual disabilities at general population level. In order to ensure that participants from various countries responded in accordance with a uniform definition of 'intellectual disabilities', the term was explicitly defined in the survey as "challenges some people face in learning and often communicating which, in interaction with various barriers, may hinder their full and effective participation in society on an equal basis with others."

The survey was available in English, Arabic, French, German and Spanish - on visiting the survey site, participants were able to choose their preferred language. An advertisement/e- 
mail invitation was developed which outlined the survey and made it clear that it was targeted primarily at researchers and representatives of organisations or advocacy groups in the intellectual disability field. The survey and invitation email were piloted with researchers in Europe, South America, the Middle East and East Asia as well as with representatives of Inclusion International to ensure that both the contents and language were appropriate to a range of contexts and respondents. Revisions were made in response to comments received during the pilot. Examples of these revisions are: the term 'hate crime' was more clearly defined; the word 'still' was removed from the draft question "Does your country [still] have institutional settings ( $\underline{\text { not }}$ for the primary purpose of education) where people with ID live?", as one reviewer commented that the term could be perceived as judgmental of those countries that do have such institutions; a space was added for optional open comments at the end of every section, as a reviewer suggested that such space would allow respondents to note any additional thoughts that were not inherent in the answers provided. Furthermore, all versions of the survey were piloted with at least one native speaker of the respective language, who was an expert in the field of intellectual disability, and revisions were made in line with their comments.

\section{Procedure}

The survey was advertised via email and advertisements distributed by the multinational organisations Inclusion International, Leonard Cheshire Disability, and IASSID and with support from Special Olympics, as well as through contacts of the research team. Respondents were encouraged to forward information about the study to other interested parties in their region. Responses were collected during the first quarter of 2015 using the survey software Qualtrics. Although respondents had the option of skipping open comments fields in 
the survey, they were required to respond to all other questions, where necessary choosing the 'not sure' or 'not applicable' response, resulting in no missing data.

The study was approved by the first authors' institutional Research Ethics Committee (Project ID: 0960/001). Participation was entirely voluntary and it was at participants' discretion whether they provided their name and organisational affiliation and agreed to be named as contributors in the final study report.

\section{Data Analysis}

Responses were analysed using Excel and SPSS. In addition to frequencies and percentages, cross-tabulations were computed according to the seven UN regions and four World Bank income categories. To assess the quality of the information collected, the level of agreement between different informants in relation to four key factual questions in the survey was examined. Intra-class correlation coefficients (ICCs) were calculated for the country within each UN region with the largest number of responses (Argentina, Australia, Israel, the UK and the USA). It was not possible to calculate ICCs for countries in Asia or Africa, as the respective samples for individual countries were too small. For three of the four questions (where children with intellectual disabilities attend school; whether residential institutions, not for the primary purpose of education, still exist and if so of what size they are; and whether there is an active programme underway to close residential institutions) all ICCs were above 0.70, indicating a high level of agreement between respondents, irrespective of the respondent's role. For the forth question, whether disability hate crime is recognised in law, ICCs were fair in some cases, indicating confusion whether disability hate crime is recognised as a distinct entity in law, see Table 1.

- Insert Table 1 about here - 
Given the generally high level of agreement between raters, we conducted further analyses by country, rather than subdividing by respondent type, but note a need for caution in drawing conclusions from our findings on disability hate crime.

\section{Results}

While diagnostic labels facilitate communication and are often used to regulate access to resources, the power of labels to increase the separation between "us"' and "them," and to foster negative emotional reactions and discrimination has been widely noted (e.g. Link, Yang, Phelan \& Collins, 2004). To gauge the extent to which particularly derogatory labels are still in use when referring to intellectual disability, we asked survey respondents to tell us what term is most commonly used by lay people and in the media in their country when referring to the condition. Terms in common use differed above all by income category of the country. Generally speaking, in higher income countries more progressive or acceptable terms such as 'intellectual disability' were reported to be in common use, whereas in lower income countries more derogatory terms such as 'mentally retarded' but also 'retard', 'mad' and 'fool' still appear to be in common use. Of note though, the relationship between income and adoption of more progressive terminology was by no means without exception, and in many high income countries very derogatory terms were reportedly still widely used. Confusion among lay people between intellectual disability and mental health problems was widely reported, regardless of country income.

\section{Public attitudes}

Asked about general attitudes and beliefs relating to intellectual disability, participants described the presence in many countries of progressive attitudes and openness among the public and the media towards inclusion. Such positive attitudes were typically described as 
developing over recent decades, thanks to marked changes and actions aimed at improving integration, and the work of non-governmental organisations (NGOs) and parents to raise awareness and advocate for inclusion. However, despite broad agreement with the principle of inclusion, in many countries the general public reportedly continued to view inclusion as impractical and unachievable, and view specialist educational and residential settings as best placed to meet the needs of persons with intellectual disabilities. In many high income countries a 'not in my own backyard' attitude appeared to persist, as did fears that inclusion of people with intellectual disabilities will deplete the resources and achievements of those without disabilities, particularly in school and work environments. In many LMICs, children and adults with intellectual disabilities often still faced high levels of stigma and had their fundamental rights and freedoms denied. Their invisibility was accompanied by low expectations of people with intellectual disabilities - in many countries they were still widely viewed as incapable, unable to live independently or contribute to society. Respondents noted that in many parts of Africa and Asia, in former member states of the Soviet Union, and in some parts of South and Central America there was often still an active desire to segregate people with intellectual disabilities from society due to deep rooted prejudice. Participants suggested that in former Soviet Union countries such prejudice relates more to their marginalisation in the labour market, whereas in many African and Asian countries it exists in large part against a background of misconceptions and stigmatising beliefs about the causes of intellectual disability.

\section{Progress towards inclusive education}

The right of children with intellectual disabilities not only to education, but also to inclusive education as the default has been firmly enshrined in international policy for two decades (UNESCO, 1994). However, these rights are frequently not implemented. Not only 
are many children with intellectual disabilities often still educated in segregated learning environments, but in many countries they are denied the right to education altogether and are among the most marginalised of children (UNESCO, 2015). Asked where children with intellectual disabilities are typically educated in their country, a broad range of models were in evidence, see Table 2.

- Insert Table 2 about here -

At least in some countries there appeared to be a clear willingness on the part of the government and education system to ensure that children with intellectual disabilities attend inclusive (mainstream) schools as default, and that reasonable adjustments were made to inclusive learning environments to accommodate the needs of such children. However, in our survey such countries appeared to be very much in the minority. In this study, Canada and Italy emerged as the only countries where all (Italy) or most (Canada) respondents reported that children with intellectual disabilities typically attend inclusive schools. Countries (or territories) in which respondents said children with intellectual disabilities were often not sent to school at all include: the Dem. Rep. of the Congo, Hong Kong, India, Liberia, Nepal, Nigeria, Sierra Leone and Uganda. They reportedly either attended 'special' (segregated) schools or are often not sent to school at all in Albania, Bangladesh, Bulgaria, Iran, Kenya, Paraguay, and Russia. We must emphasise that, as noted, the data presented here only pertains to around half of the world's countries- it is likely that there are many more countries where children are either denied their right to education altogether or only have access to segregated educational settings. Similarly it needs stressing that in at least some of the countries listed above many children without disabilities are not regularly sent to school for a host of reasons. This is particularly the case in rural and/or economically deprived areas. The fact that in many countries a two tier education system exists (inclusive alongside segregated 'special' schools), raises the question 
how the decision to send some children with intellectual disabilities to inclusive schools and others to special schools is reached, and to what extent it is based on evidence about the setting likely to promote the best outcomes for the individual child and child and parental choice.

\section{Progress on deinstitutionalisation}

It is now widely recognised that institutional environments are damaging to a person's development and well-being, make them more vulnerable to abuse and violate their right to freedom. The UN CRPD explicitly states that all persons with disabilities have the fundamental right to freedom. Nonetheless in many countries children and adults with intellectual disabilities continue to be placed in residential care institutions with little choice and few freedoms, often for large parts of their lives. Historically, the large scale institutionalisation of people with intellectual disabilities was largely confined to higher income countries and Eastern Europe, and can be traced as much to a belief that their needs were best met in specialised institutional environments as to a desire to segregate them from society. We asked survey respondents whether residential institutions for persons with intellectual disabilities, not for the primary purpose of education, are still in existence in their country and how big the largest such institutions are, see Table 3.

- Insert Table 3 about here -

An active programme aimed at closing remaining larger institutions was reported by $35.7 \%(n=238)$ of respondents, $20.7 \%(n=138)$ said no such closure plans were underway in their country, and 30\% ( $\mathrm{n}=200)$ were unsure or stated that this question was not applicable as no (large) institutions ever existed or remained in their country. Only a few countries that traditionally had large institutions, including Australia, Italy, New Zealand, Norway and the UK, had closed all. In the USA a very mixed picture was reported, with some states having 
closed all large institutions, many others downsizing or actively closing them, but some states highly resistant to closing remaining institutions. In Canada similarly variation by province was noted. In other countries, such as South Africa, institutions had been reduced in size but the political will and investment needed to close them was reportedly lacking. In many countries, such as Finland, Israel and Ireland, the closure of large institutions had been very slow, with thousands of citizens still living in such places. In other countries, such as Norway and the UK, large institutions had been closed but replaced with new, smaller specialist quasiinstitutions where residents similarly have little choice and control over their lives.

Many countries in Asia, Africa and South and Central America never had large institutions, care for people with intellectual disabilities always having been seen as the family's and not the state's responsibility. Importantly, participants noted that in countries where families are expected to care for their relatives with disabilities and where no or few support services exist, family support was by no means guaranteed; in addition, many people with intellectual disabilities are left utterly unsupported when their parents die. Furthermore, some countries, such as China, in the wake of intense development and urbanisation and the associated intense pressures on families, were seeking to establish institutions, apparently paying little attention to their harmful effects and violation of people's rights.

\section{Actions to combat Acts of Abuse, Harassment and Violence against People with}

\section{Intellectual Disabilities}

We sought to ascertain to what extent, seven years after the CRPD came into force, people with intellectual disabilities had recourse to the law when they were the victims of abuse, harassment and violence directed at them because others perceive them to have a disability. Accordingly, we asked respondents whether such offences are recognised as distinct criminal offences. Overall, nearly half of all respondents thought that they were, around a fifth 
reported that they were not, and a third were unsure. These proportions varied considerably across the regions, see Table 4.

- $\quad$ Insert Table 4 about here -

Responses indicated that in some countries people with intellectual disabilities appear to have very little recourse to legal protection if they are victimized because of their disability. In many others hostile actions against someone with a disability are covered under (disability) discrimination legislation. As Fiala-Butora and Stein (2016) note, this means that the victim may only have the option of a civil course of action, and there is no recourse to higher sentencing in recognition of the aggravated and prejudicial nature of such crimes, or of official recording and recognition of hostile acts against people with disabilities.

Asked whether active efforts were underway by the courts or criminal justice system to tackle disability hate crime, the proportion of respondents answering in the affirmative was lower compared to the question regarding recognition of such crimes, in many places by a large margin, see Table 5. In South and Central America and the Caribbean, 43\% of respondents said that disability hate crime was recognised in law but only $33 \%$ reported that active steps were being taken to combat it. While in Africa 60\% said that disability hate crimes were recognised in law, only $27 \%$ were aware of any action by the courts or justice system to combat such crimes. In other regions the figures suggested that disability hate crime may not be recognised in law as a distinct offence but that action was taken nonetheless by the courts and criminal justice system to tackle crimes against people with disabilities that are informed by prejudice or hostility.

- $\quad$ Insert Table 5 about here - 
Action by the police or other law enforcement agencies to combat disability hate crime was generally deemed similarly or considerably less likely compared to action by the courts or criminal justice system. The proportion by world region who said their country's police or other law enforcement agencies made active efforts to tackle disability hate crime were: Asia: $17.5 \%$; Europe: 38.1\%; MENA: 25\%; North America: 23.8\%; Oceania: 23.8\%; South \& Central America and the Caribbean: 22.1\%; and Sub-Saharan Africa: 27\%. These figures paint a worrying picture of the extent to which, in practice, people with intellectual disabilities may have recourse to legal protection when they are the victims of abuse, harassment or violence directed at them because of their disability and associated vulnerability. Of note, responses to disability hate crimes, including punishments (or lack thereof), should be seen in the broader context of the law enforcement and judicial systems of each country, which may have limitations in the first place. Of note, there was a high proportion of 'unsure' responses to the initial question about recognition of disability hate crime and in some instances respondents from the same country disagreed on this item. This indicates that the findings relating to both recognition of and responses to disability hate crime should be viewed with considerable caution. We expect that despite providing a clear definition, the fact that in most parts of the world any crime against a person with a disability at best may be treated like any other crime, without recognition of its potential roots in prejudice, left many respondents confused about the notion of a distinct criminal offence.

\section{Actions aimed at Raising Awareness and Challenging Stigma}

Respondents were asked about actions that aim to raise awareness of intellectual disability, to encourage more positive attitudes and to tackle prejudice and discrimination within the community and society at large, rather than solely among specific groups more likely to have contact with individuals with intellectual disabilities, such as carers, teachers or health 
professionals. In particular we asked about initiatives targeting (1) children/young people within education settings; (2) the wider community through local or regional initiatives; and (3) society at large through initiatives implemented at national level. Details of all initiatives cited by respondents were scrutinised, where necessary by researching and examining details about named initiatives. Only those initiatives that focused at least in part on intellectual disability, rather than disability generally or conditions that only partially overlap with intellectual disability, such as autism, were included in the results presented here. (Full details of all initiatives identified are available at www. - link withheld to ensure anonymous review.) Figure 1 presents the number of initiatives in each of the three categories, rather than the number of respondents who named respective initiatives, by region to account for the same initiative being named by multiple respondents.

- Insert Figure 1 about here -

As is evident from the figure, we identified very few interventions targeting young people within education settings or those seeking change through national level initiatives in world regions other than Europe and North America. Despite noting concerns about often high levels of stigma faced by people with intellectual disabilities and their families in their respective countries, the 40 respondents from Asia named a few small scale, local initiatives but were unable to name any initiatives targeting school children or ones at national level. Similarly, we were told of intense stigma in many African countries but the small number of initiatives identified stood in no relation to the perceived need for such actions and initiatives reported were overwhelmingly

instigated and led by parents of individuals with intellectual disabilities, with no or little recourse to funding or external support. 
The extent to which respondents from different country income categories were aware of specific initiatives aimed at raising awareness of intellectual disability and promoting positive attitudes is shown in Figure 2. We must stress again that different UN regions and World Bank income categories were not equally represented in the data presented here.

- Insert Figure 2 about here -

\section{Discussion}

The country specific accounts by 667 experts and advocates active in the (intellectual) disability field across 88 countries around the globe summarised here present an overview that was simultaneously encouraging and disheartening. We received many reports that in many parts of the world much progress has been made towards achieving equal rights and social inclusion, enshrined in the CRPD, for children and adults with intellectual disabilities. In countries where (self-) advocacy is well advanced and equality of opportunity is reflected in policy, laws and service provision, there appeared to be widespread support for these aims within society at large. However, even in these places survey respondents noted frequent double standards - alongside the explicit message that individuals with intellectual disabilities were valued as equals and welcome in all spheres of daily life, respondents noted frequent concerns within society that their inclusion in normative activities, particularly education and work would negatively affect the opportunities and advancement of those without intellectual disabilities. Where such attitudes reduce opportunities for social inclusion this bodes badly not just for the rights of persons with intellectual disabilities but also for efforts to improve attitudes among the public, given that contact appears key to their success (Blundell, Potts, Das \& Scior, 2016; Macmillan, Tarrant, Abraham \& Morris, 2014; Scior \& Werner, 2014). 
The present survey's findings concur with the conclusions of the World Disability Report WHO, 2011) that in many parts of the world, particularly in LMICs but also in some former member states of the Soviet Union, the life chances of people with intellectual disabilities are often still poor, and support and advocacy are almost entirely their families' responsibility. Although the vast majority of people with intellectual disabilities worldwide live in such countries, they are largely invisible in the intellectual disability literature and in research, which are heavily dominated by reporting on highly developed countries. Our finding of a large imbalance in terms of where prejudice and discrimination appear to be at their most intense and where initiatives are underway to tackle stigma are partly but by no means wholly explained by the overrepresentation of high income countries.

While some may argue that tackling severe resource limitations should be a priority over any focus on attitudes, we believe developing resources needs to go hand in hand with educating the public about intellectual and developmental disabilities and tackling the intense stigma often associated with them. In this regard, commitments made by governments and multilateral organisations at the recent Global Disability Summit (UK Government, 2018) to do more to reduce disability stigma are very welcome - time will tell whether they are followed up with actions.

The argument that high and lower-income countries can learn from one another regarding how to (effectively) tackle stigma (McConkey, Kahonde, McKenzie, 2016) certainly found support in this study in the many inspiring examples of anti-stigma initiatives we heard of from very diverse parts of the world. It was striking though that very few initiatives had been formally evaluated and thus a fairly rich catalogue of anti-stigma strategies had generated only a very limited evidence base to inform future efforts. 
A number of key limitations to the findings reported here need noting. A major hurdle for any global comparative study is the immense variation that exists across countries, including those that fall within the same world region or income category. It should be borne in mind that countries subsumed under broad UN regions differ markedly in their cultural, religious and economic characteristics. In the present study we tried to reflect some of that variation but are mindful that in summarising the data collected we are guilty of appearing to overstate commonalities and minimise variation. Similarly, our findings were strongly weighted toward high-income countries, particularly those in Europe and North America, and more detailed evidence is needed on LMICs. While accessing data from 88 countries is a strength of the study, breadth inevitably comes at the expense of depth. We obtained responses from an average eight respondents per country but in many cases fewer. While we recruited respondents through multinational organisations that are well regarded in the disability field, the fact that respondents were ultimately self-selected means their responses may not have been representative or in fact accurate. We tried to address this risk by assessing correspondence between respondents' answers to key fact-based questions and found this to be good for three of the four issues examined.

A further limitation concerns the fact that the response rate cannot be ascertained due to the methodology - the survey was distributed to the global lists of multiple organisations and further shared via snowballing, hence it is unknown how many individuals/organisations received the survey, what proportion responded, and whether, for example, this may have differed by country or world region. Finally, while the responses of experts and representatives of organisations for people with (intellectual) disabilities provided us with a broad brush understanding of societal attitudes and corresponding initiatives unique to each country, it is important to consider that these evaluations may not reflect wider opinions within those 
countries. Accessing these will require more in-depth research with representative general population samples.

A further key challenge for studies such as this one intended for a global audience is that definitions and terminology can vary hugely between countries. In the present survey we defined key terms, such as 'intellectual disability' and 'disability hate crime', to provide a clear context for the information sought. However, it is likely nonetheless that in places participants' responses were guided by their own and local understandings of key concepts. We refrained from defining terms such as 'awareness raising' and 'promoting positive attitudes' but instead examined initiatives identified by respondents in detail, wherever possible, and reached a judgement whether the initiatives mentioned did in fact seek to educate members of the general population or specific sub-groups about intellectual disability or to promote more positive attitudes (and behaviour) towards people with intellectual disabilities.

\section{Conclusions}

In view of evidence of continuing prejudice towards this population, more action is needed to tackle negative attitudes, and promote active engagement and regular social interactions between persons with intellectual disabilities and their fellow citizens without intellectual disabilities. There appears to be a particularly urgent need for such efforts in many LMICs where equal rights for persons with intellectual disabilities appear but a distant vision. Research is needed that identifies what initiatives aimed at promoting more positive attitudes towards people with intellectual disabilities work in different settings. 


\section{References}

Cummins, R. A., \& Lau, A. L. (2003). Community integration or community exposure? A review and discussion in relations to people with an intellectual disability. Journal of Applied Research in Intellectual Disabilities, 16, 145-157.

Fiala-Butora, J. \& Stein, M. (2016). The law as a source of stigma or empowerment: Legal capacity and persons with intellectual disabilities. In K. Scior \& S. Werner (Eds), Stigma and intellectual disability: Stepping out from the margins (pp. 195-208). Basingstoke: Palgrave Macmillan.

Ingstad, B. \& Reynolds Whyte, S. (Eds) (1995). Disability and culture. Berkeley, CA: Univ. of California Press.

Link, B.G., Yang, L.H., Phelan, J.C., \& Collins, P.Y. (2004). Measuring mental illness stigma, Schizophrenia Bulletin, 30(3), 511-541.

Macmillan, M., Tarrant, M., Abraham, C., \& Morris, C. (2014). The association between children's contact with people with disabilities and their attitudes towards disability: A systematic review. Developmental Medicine \& Child Neurology, 56 , 529-546.

Maulik, P.K., Mascarenhas, M.N., Mathers, C.N., Dua, T., Saxena, S. (2011). Prevalence of intellectual disability: A meta-analysis of population-based studies. Research in Developmental Disabilities, 32, 419-436.

McConkey, R., Kahonde, C. \& McKenzie, J.A. (2016). Tackling stigma in developing countries: The key role of families. In K. Scior \& S. Werner (Eds), Stigma and intellectual disability: Stepping out from the margins (pp. 179-194). Basingstoke: Palgrave Macmillan.

McKenzie, J.A., McConkey, R. \& Adnams, C. (2013). Intellectual disability in Africa: Implications for research and service development. Disability \& Rehabilitation, 35, $1750-1755$. 
Merrells, J., Buchanan, A., \& Waters, R. (2018). The experience of social inclusion for people with intellectual disability within community recreational programs: A systematic review. Journal of Intellectual \& Developmental Disability, 43(4), 381-391.

Mung'omba, J. (2008). Comparative policy brief: Status of intellectual disabilities in the Republic of Zambia. Journal of Policy \& Practice in Intellectual Disabilities, 5 (2), $142-144$

Scherzer, A. L., Chhagan, M., Kauchali, S., \& Susser, E. (2012). Global perspective on early diagnosis and intervention for children with developmental delays and disabilities. Developmental Medicine and Child Neurology, 54(12), 1079-1084.

Scior, K. (2011). Public awareness, attitudes and beliefs regarding intellectual disability: A systematic review. Research in Developmental Disabilities, 32, 2164-2182.

Scior, K. \& Werner, S. (2015). Changing attitudes to learning disability: A review of the evidence. Mencap, University College London \& the Hebrew University of Jerusalem.

Siperstein, G., Norins, J., Corbin, S. \& Shriver, T. (2003). Multinational study of attitudes toward individuals with intellectual disabilities. Washington DC: Special Olympics.

UK Government (2018). Press release - Global Disability Summit sparks 170 commitments to tackle stigma and discrimination against people with disabilities. Retrieved 20.12.2018 from www.gov.uk/government/news/global-disability-summit-sparks-170commitments-to-tackle-stigma-and-discrimination-against-people-with-disabilities

UNESCO (1994). The Salamanca Statement and framework for action on special needs education. Adopted by the World Conference on Special Needs Education: Access and Quality. Salamanca, Spain, 7-10 June 1994.

UNESCO (2015). Fixing the broken promise of education for all: Findings from the Global initiative on out-of-school children. Montreal: UNESCO Institute for Statistics. 
United Nations General Assembly (2006). Convention on the rights of persons with disabilities. New York, NY: United Nations.

Van Asselt, D., Buchanan, A., \& Peterson, S. (2015). Enablers and barriers of social inclusion for young adults with intellectual disability: A multidimensional view. Journal of Intellectual and Developmental Disability, 40(1), 37-48.

World Health Organization (2007). WHO Atlas: Global Resources for Persons with Intellectual Disabilities. Geneva: WHO.

World Health Organization \& World Bank (2011). World Report on Disability. Geneva: WHO. 


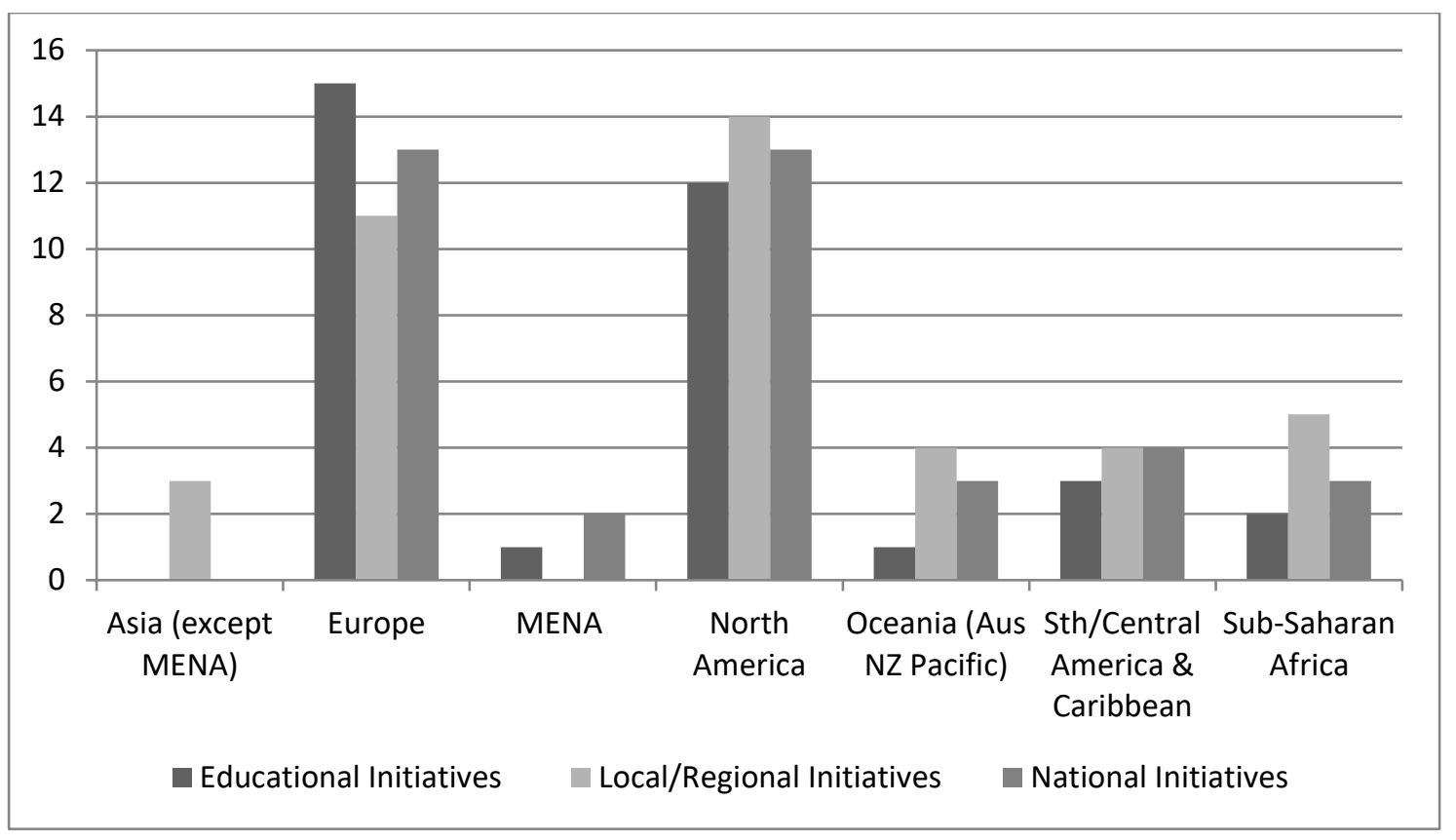

Figure 1 - Number of educational, local/regional and national initiatives by UN region

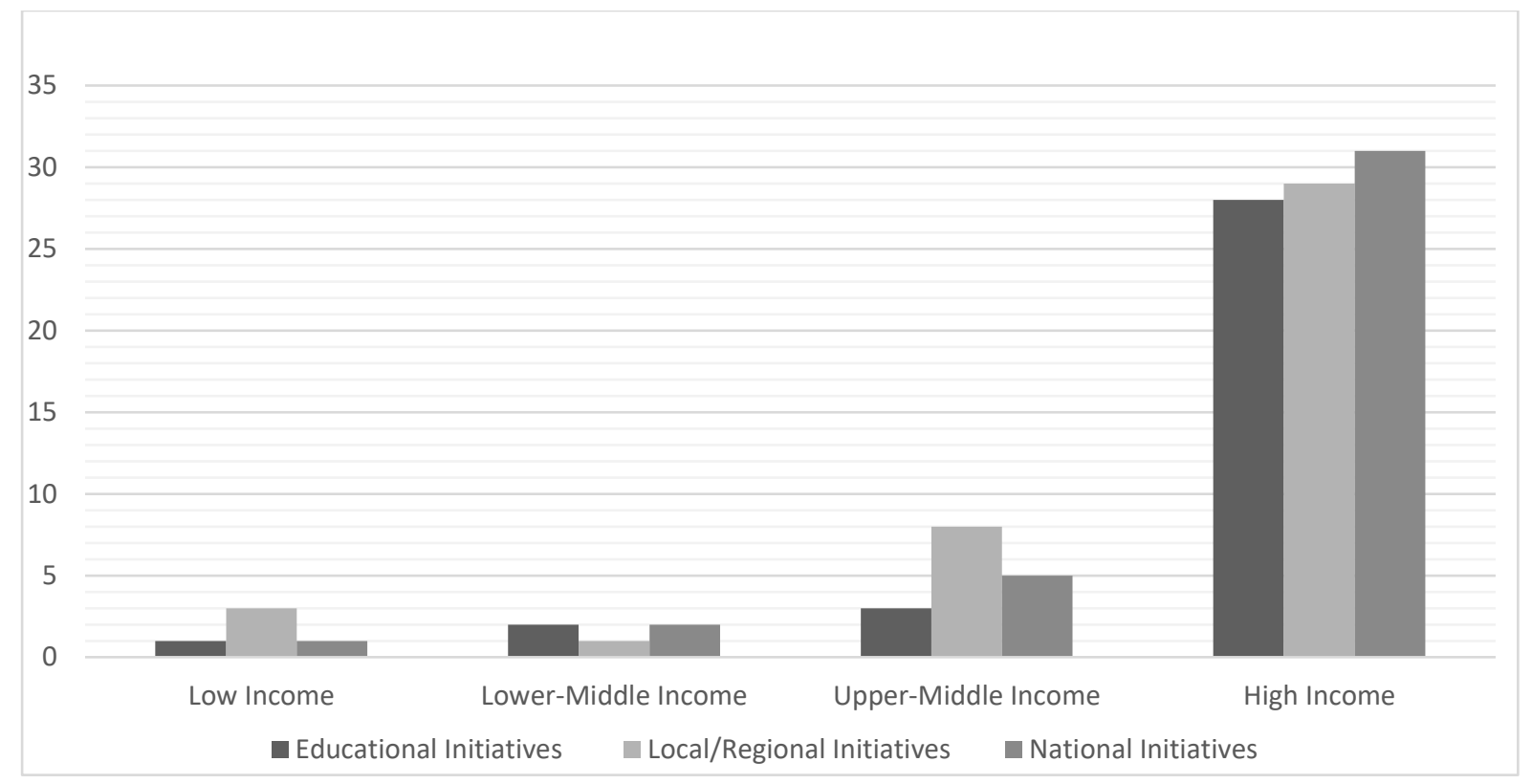

Figure 2 - Number of educational, local/regional and national initiatives by country income 
Table 1. Intraclass correlation coefficients for key factual information for 5 countries

\begin{tabular}{lclcccc}
\hline Country & $\mathrm{N}$ & UN Region & Schooling $^{1}$ & $\begin{array}{c}\text { Institution } \\
\text { Presence }^{2}\end{array}$ & $\begin{array}{c}\text { Institution } \\
\text { Closures }^{3}\end{array}$ & $\begin{array}{c}\text { Dis. Hate } \\
\text { Crime Law }^{3}\end{array}$ \\
\hline Argentina & 44 & Sth America & 0.96 & 0.77 & 0.74 & 0.89 \\
Australia & 48 & Oceania & 0.99 & 0.82 & 0.98 & 0.58 \\
Israel & 17 & MENA & 0.92 & 0.95 & 0.70 & 0.56 \\
UK & 45 & Nth Europe & 0.99 & 0.74 & 0.94 & 0.99 \\
USA & 104 & Nth America & 0.99 & 0.98 & 0.99 & 0.92 \\
\hline
\end{tabular}

${ }^{1}$ Response options: (1) all/most in mainstream schools; (2) both in mainstream and special schools; (3) all/most in special schools; (4) typically not sent to school at all; (5) unsure

${ }^{2}$ Response options: (1) yes, where $100+$ people live; (2) yes, where 50 to 100 people live; (3) yes, where 20 to 50 people live; (4) yes, where 10 to 20 people live; (5) yes, but only as units for short term assessment/ treatment or as secure accommodation (i.e. for offenders with ID); (6) no; (7) unsure

${ }^{3}$ Response options: (1) yes; (2) no; (3) unsure

Table 2. Where children with intellectual disabilities are typically schooled

\begin{tabular}{lcc}
\hline Where Schooled & $\begin{array}{c}\text { Number of } \\
\text { Responses }\end{array}$ & $\begin{array}{c}\text { Proportion of } \\
\text { Responses }\end{array}$ \\
\hline All/most in mainstream schools & 108 & $16.2 \%$ \\
In both mainstream \& special schools & 385 & $57.7 \%$ \\
All/most in special schools & 136 & $20.4 \%$ \\
Either special school or not sent to school at all & 13 & $1.9 \%$ \\
Typically not sent to school at all & 18 & $2.7 \%$ \\
Unsure & 7 & $0.1 \%$ \\
Total & 667 & $100 \%$ \\
\hline
\end{tabular}


Table 3: Largest residential institutions for adults by size

\begin{tabular}{lcc}
\hline Size of Remaining Institutions & $\begin{array}{c}\text { Number of } \\
\text { Responses }\end{array}$ & $\begin{array}{c}\text { Proportion of } \\
\text { Responses }\end{array}$ \\
\hline$>100$ residents & 240 & $36 \%$ \\
50 to 100 residents & 82 & $12.3 \%$ \\
20 to 50 residents & 70 & $10.5 \%$ \\
10 to 20 residents & 41 & $6.1 \%$ \\
$<10$ residents & 57 & $8.5 \%$ \\
Only for short term assessment/treatment or as & 58 & $8.7 \%$ \\
secure accommodation & 104 & $15.6 \%$ \\
There are no (remaining) residential institutions & 89 & $13.3 \%$ \\
Unsure & & \\
\hline
\end{tabular}

Note: Numbers exceed 667 as some respondents indicated that two of the response options applied

Table 4: Recognition of disability hate crime as a criminal offence by region

\begin{tabular}{lcccc}
\hline Region & Yes & No & Unsure & Total \\
\hline Sub-Saharan Africa & $60.0 \%(21)$ & $11.4 \%(4)$ & $28.6 \%(10)$ & 35 \\
MENA (Middle East \& N. Africa) & $28.6 \%(8)$ & $25.0 \%(7)$ & $46.4 \%(13)$ & 28 \\
Asia (except MENA) & $26.3 \%(10)$ & $42.1 \%(16)$ & $31.6 \%(12)$ & 38 \\
Europe & $54.0 \%(114)$ & $14.2 \%(30)$ & $31.8 \%(67)$ & 211 \\
South/Central America \& Caribbean & $42.7 \%(50)$ & $31.6 \%(37)$ & $25.6 \%(30)$ & 117 \\
North America & $49.7 \%(78)$ & $9.6 \%(15)$ & $40.8 \%(64)$ & 157 \\
Oceania (Aus, NZ, Pacific) & $41.9 \%(26)$ & $22.6 \%(14)$ & $35.5 \%(22)$ & 62 \\
Total & $47.4 \%(307)$ & $19.0 \%(123)$ & $33.6 \%(218)$ & 648 \\
\hline
\end{tabular}


Table 5: Action by criminal justice system to tackle disability hate crime by region

\begin{tabular}{lcccc}
\hline Region & Yes & No & Unsure & Total \\
\hline Sub-Saharan Africa & $27.0 \%(10)$ & $37.8 \%(14)$ & $35.1 \%(13)$ & 37 \\
MENA (Middle East \& N. & $39.3 \%(11)$ & $25.0 \%(7)$ & $35.7 \%(10)$ & 28 \\
Africa) & $12.5 \%(5)$ & $42.5 \%(17)$ & $45.0 \%(18)$ & 40 \\
Asia (except MENA) & $42.2 \%(92)$ & $12.8 \%(28)$ & $45.0 \%(98)$ & 218 \\
Europe & $32.8 \%(40)$ & $30.3 \%(37)$ & $36.9 \%(45)$ & 122 \\
South \& Central America \& the & $45.3 \%(72)$ & $10.1 \%(16)$ & $44.7 \%(71)$ & 159 \\
Caribbean & $33.3 \%(21)$ & $20.6 \%(13)$ & $46.0 \%(29)$ & 63 \\
North America & $37.6 \%(251)$ & $19.8 \%(132)$ & $42.6 \%(284)$ & 667 \\
Oceania (Aus, NZ, Pacific) & & & & \\
Total & & & & \\
\hline
\end{tabular}




\section{Appendix}

\section{Full survey}

\section{Introduction}

This survey focuses specifically on people who are identified as having an intellectual disability*. It seeks information about national efforts to raise awareness and combat negative and harmful practices relating to people with intellectual disabilities. Article 8 of the UN Convention on the Rights of Persons with Disabilities requires governments to work towards greater equality and non-discrimination through raising awareness throughout society and combatting prejudices and harmful practices. Whether or not there has been much attention paid to the UN Convention in your country, we are interested in hearing about efforts made towards these aims in relation to people with intellectual disabilities.

*The term intellectual disabilities (ID) refers to challenges some people face in learning and often communicating which, in interaction with various barriers, may hinder their full and effective participation in society on an equal basis with others. Typically persons with ID experience these challenges from birth or an early age and usually require some form of lifelong support.

\section{About you}

Your country:

Your name:

Name of your organisation:

Position/role:

b. How did you hear about this survey?

Via Inclusion International

Via Leonard Cheshire Disability

Via IASSID

Direct communication from project team

Sent to me by someone else

Other

c. Does your work/activity relate mainly to

People with physical and/or sensory disabilities

People with intellectual disabilities (ID)

Both people with ID and other disabilities

Other (Please specify):

d. Are you completing this survey as a (Please select all that apply)

Representative of an organisation focused mainly on people with ID (and their families)

Representative of an organisation focused on people with disabilities generally

Expert or someone with a strong interest in the ID field

Expert or someone with a strong interest in the disability field (not specific to ID)

None of the above (if this option was chosen, respondent received the following response and they survey was stopped at this point.

Thank you very much for your time. The remainder of this survey is only relevant to representatives of disability organisations or experts in this field. Do you know of any such person in your country who 
may be interested in taking part? If so, please forward the invitation to them or provide an email address for them below.

\section{Part 1}

This first part consists of some general questions about people with ID in your country.

1.1 What term is most commonly used among lay people and in the media in your country to refer to ID? (Please provide the term in your country's language)

1.2a When developmental delay in a child/adult is apparent, to what extent is assessment offered to diagnose/establish whether ID is present?
Never
Rarely
About $25 \%$ of the time
About $50 \%$ of the time
About $75 \%$ of the time
Routinely
Unsure

$1.2 \mathrm{~b}$ If assessment is recommended, for what main purpose? (Select all that apply)

To identify needs of the individual and what support is required

To establish eligibility for specialist support

To establish eligibility for financial support

To justify exclusion from mainstream activities/services

1.3 In your country, are there special schools (where children with ID are educated separately from their peers who do not have a disability)?

Yes

Not special schools, but special units within mainstream schools

No special schools or units exist

Unsure

1.4 Where do children with ID go to school in your country?

All/most in mainstream schools

Both in mainstream and special schools

All/most in special schools

Typically not sent to school at all

Unsure 
1.5a Does your country have institutional settings (not for the primary purpose of education) where people with ID live?

Yes, where $100+$ people live

Yes, where 50 to 100 people live

Yes, where 20 to 50 people live

Yes, where 10 to 20 people live

Yes, but only as units for short term assessment/ treatment or as secure accommodation (i.e. for offenders with ID)

No

Unsure

$1.5 \mathrm{~b}$ If yes, is there an active programme underway aimed at closing most such institutions?

Yes

No

Unsure

1.6 Do you have any comments about beliefs people in your country commonly hold about the best place for people with ID to be schooled and/or live?

\section{$\underline{\text { Part } 2}$}

In the second part of this survey we ask about action at national level, but would also very much like to hear of smaller and local good practice examples in your country.

2.1a Are there any active non-governmental organisations (including charitable organisations) or networks in your country that focus on promoting and protecting the freedoms and human rights of people with ID?
Yes
No
Unsure

$2.1 \mathrm{~b}$ If yes, what is/are their name(s)?

2.2 Is disability hate crime ${ }^{\star}$ recognised as a criminal offence?
Yes
No
Unsure

"A 'disability hate crime' refers to any criminal offence which is motivated by hostility or prejudice based on a person's disability.

2.3 Are there active efforts to tackle disability hate crime:

by the courts or justice system?

by the police or other law enforcement agency?

at a community/society level? 
2.4a Are you aware of any efforts targeting children within the education system aimed at:

raising awareness what ID is?

encouraging respect for the rights of people with ID?

recognising the abilities and (potential) contribution of people with ID?

promoting positive attitudes towards people with ID?

encouraging more positive interactions with people with ID?

2.4b If yes, please tell us a bit more about them (including what is being done, name of the project, and, where available, who leads the project and contact details or internet address)

2.4c Are you aware of any report or evaluation on these efforts? Any other information to judge the success of the project?

2.5a Are you aware of any smaller scale, local efforts aimed at

$\begin{array}{llll} & \text { Yes } & \text { No } & \text { Unsure } \\ \text { raising awareness what ID is? } & \square & \square & \square \\ \text { encouraging respect for the rights of people with ID? } & \square & \square \\ \text { recognising the abilities and (potential) contribution of people with } & \square \\ \text { ID? } & \square & \square \\ \text { promoting positive attitudes towards people with ID? } & \square & \square & \square \\ \text { encouraging more positive interactions with people with ID? } & \square & \square\end{array}$

$2.5 \mathrm{~b}$ If yes, please tell us a bit more about them (including what is being done, name of the project, and, where available, who leads the project and contact details or internet address)

2.5c Are you aware of any report or evaluation on these efforts? Any other information to judge the success of the project?

2.6a Are you aware of any national (or regional) efforts (e.g. campaigns) at societal level aimed at Yes No Unsure

raising awareness what ID is?

encouraging respect for the rights of people with ID?

recognising the abilities and (potential) contribution of people with ID?

promoting positive attitudes towards people with ID?

encouraging more positive interactions with people with ID? 
2.6b If yes, please tell us a bit more about them (including what is being done, name of the project, and, where available, who leads the project and contact details or internet address)

2.6c Are you aware of any report or evaluation on these efforts? Any other information to judge the success of the project?

2.7 Are you aware of any other good practice examples not already mentioned? Please help us find these (names, organisations, year, contact details, internet address - anything that can help us find the project) 